\title{
The Role of Food Energy Technologies in Solving Global Mankind Problems
}

\author{
Burdo O. G. \\ Odessa National Academy of Food Technologies, Odessa, Ukraine
}

\begin{abstract}
The analysis of the Club of Rome global forecasting mode was carried out. A critical analysis of the Club of Rome activity was given. The purpose of the work is to establish the tasks of the food industry in solving the global problems of mankind. It is noted that the global crises (energy, ecology and food) are most clearly manifested in the food industry. To achieve this goal, a scientific and technical idea has been proposed that to solve the global problems the innovative technologies must be involved, which were not considered at all in the Club of Rome projects. The human development paradigm was formulated, considering the modern advances in science, technology, and nanotechnology. It was substantiated that the nanotechnology use in the food industry is attractive because the food raw materials are nano-sized structures created by nature. Local energy impact on nano-sized elements of the food raw materials can shorten the process time by the orders of magnitude. Such impacts are referred to as "nanoenergy technologies". The most significant result of the work was that the possibility was shown to control the development of the worst global crises by transferring the food industry onto the rails of the "nanoenergy technologies" and thus postpone the crises for another 10-40 years. The scientific significance of the obtained results was that such new effects as "barodiffusion" and "mechanodiffusion" were used in the work. The practical significance of the work was that a technological line for deep processing of food waste was proposed.

Keywords: nanotechnologies, hybrid processes, electrodynamic technologies, environmental industry, food industry waste, globalistics.

DOI: https://doi.org/10.52254/1857-0070.2021.3-51.09

UDC: 620.9:620.3:664.012.3:502.174.1:005.44
\end{abstract}

\section{Rolul tehnologiilor energetice alimentare în soluționarea problemelor globale ale omenirii}

Burdo O.G.

Academia Națională de tehnologii alimentare din Odesa, Odesa, Ucraina

Rezumat. Se efectuează analiza modelului global de prognoză al Clubului de la Roma. Sunt justificate motivele lipsei rezultatelor practice ale activităților lor. Sunt identificate crizele globale, înaintate în fața omenirii pentru soluționare. Scopul lucrării este determinat - de a stabili sarcinile industriei alimentare în sluționarea problemelor globale ale omenirii. Se remarcă faptul precum că crizele globale (energie, ecologie și alimente) se manifestă cel mai clar în industria alimentară. Pentru a atinge acest obiectiv, s-a propus o idee științifică și tehnică conform căreia, în rezolvarea problemelor globale, este necesar să se implice tehnologii inovatoare, care nu au fost deloc luate în considerare în proiectele Clubului de la Roma. Analiza epocilor industriale ale dezvoltării umane este dată. Se arată că natura dezvoltării acestor ere este similară cu modelele crizelor globale. Paradigma dezvoltării umane este formulată, luând în considerare succesele moderne ale științei și tehnologiei, nanotehnologia. S-a confirmat că utilizarea nanotehnologiei în industria alimentară este atractivă, deoarece materiile prime alimentare sunt structuri de dimensiuni nanometrice create de natură. Impactul energetic local asupra elementelor nanomedicale ale materiilor prime alimentare poate scurta timpul procesului cu ordine de mărime, reduce costurile energetice și poate realiza o extracție profundă a componentelor țintă. Astfel de influențe sunt numite „tehnologii nanoenergetice Cel mai semnificativ rezultat al lucrării este că se arată că este posibil să se gestioneze dezvoltarea crizelor globale prin transferul industriei alimentare pe şinele „nanotehnologiei”, pentru a reduce severitatea acestor crizele și a le amâna pentru 10-40 de ani. . Semnificația științifică a rezultatelor obținute este că sunt utilizate noi efecte în lucrare, care se numesc „barodifuzie” și „,mecanodifuzie”.

Cuvinte-cheie: nanotehnologie, procese hibride, tehnologii electrodinamice, eco-industrie, deșeuri alimentare, globalistică.

\section{Роль пищевых энерготехнологий в решении глобальных проблем человечества Бурдо О.Г. \\ Одесская национальная академия пищевых технологий, Одесса, Украина}

Аннотация. Проведен анализ глобальной прогнозной модели «Римского клуба». Выделены глобальные кризисы, которые должно решать человечество. Дан критический анализ полувековой деятельности «Римского клуба». Обоснованы причины отсутствия практических результатов их деятельности. 
Определена цель работы - установить задачи пищевой индустрии в решении глобальных проблем человечества. Отмечено, что глобальные кризисы (энергии, экологии и пищи) наиболее ярко проявляются в пищевой индустрии. Для достижения поставленной цели предложена научно-техническая идея, что в решении глобальных задач следует привлекать инновационные технологии, которые в проектах «Римского клуба» вообе не принимались во внимание. Дан анализ индустриальных эпох развития человечества. Показано, что характер развития этих эпох подобен моделям глобальных кризисов. Сформулирована парадигма развития человечества с учетом современных успехов науки и техники, нанотехнологий. Обосновано, что применение нанотехнологий в пищевой индустрии привлекательно тем, что пищевое сырье - это созданные природой наноразмерные структуры. Локальное энергетическое воздействие на наноразмерные элементы пищевого сырья может на порядки сократить время процесса, снизить энергетические затраты, добиться глубокого извлечения целевых компонентов. Такие воздействия названы «наноэнерготехнологиями». Рассмотрены механизмы гибридных процессов. Показано, что инструментом практической реализации процессов являются электродинамические технологии. Наиболее существенным результатом работы является то, что показана возможность управлять развитием глобальных кризисов за счет перевода пищевой индустрии на рельсы «нанотехнологий», снизить остроту этих кризисов и отсрочить их на 10-40 лет. Научная значимость полученных результатов в том, что в работе используются новые эффекты, который названы «бародиффузией» и «механодиффузией». Практическая значимость работы состоит в том, что предложена технологическая линия глубокой переработки отходов с выделением функциональных компонентов. Так, из отходов выделяются резервные источники пищи и топливные пеллеты при снижении нагрузки на среду обитания.

Ключевые слова: нанотехнологии, гибридные процессы, электродинамические технологии, экоиндустрия, отходы пищевых производств, глобалистика.

\section{ВВЕДЕНИЕ}

Глобальная прогнозная модель развития человечества является фундаментальной основой современной теории глобалистики, представляет логичную обработку огромного массива информации, которая отражает ключевые вопросы жизни на планете. Заслуги и приоритет ученых Римского клуба общепризнаны и их сложно переоценить. Вместе с тем, все усилия ученых Римского клуба были направлены на призывы, на убеждения людей, что глобальные проблемы заостряются, что ими надо заниматься. Пришло время ученым разобраться с проблемами в другой плоскости - определить, что надо делать и в какой последовательности. Представляется, что для каждой отрасли экономики такие задачи должны быть разными. Автор поставил задачу обосновать пути и приоритеты в решении глобальных задач в энерготехнологиях пищевой индустрии. Это единственная отрасль, где проявляются все глобальные кризисы, и проявляются наиболее ярко. Это отрасль, которая развита и является проблемной во всех абсолютно странах и занимает лидирующие позиции по уровню потребления энергетических ресурсов. В пищевой индустрии энергетические технологии (сушка, выпарка, тепловая обработка и пр.) в значительной степени определяют как качество готового продукта, так и его себестоимость. Именно в пищевой индустрии сосредоточены проблемы энергии, экологии и пищи $[1,2]$.
В настоящий период времени одновременное решение проблем энергии, экологии и пищи позволит управлять развитием кризисов.

\section{АНАЛИЗ ЛИТЕРАТУРНЫХ ИСТОЧНИКОВ, ФОРМУЛИРОВКА ПРОБЛЕМЫ И ГИПОТЕЗ}

Вся история развития человечества свидетельствует о том, что есть четкая корреляция между уровнем потребления энергии, продолжительностью и качеством жизни. Если первобытный человек потреблял энергию только с пищей, то в развитой стране один человек стал потреблять энергии в 100 раз больше, а продолжительность его жизни выросла в среднем до 70 лет, из которых $50 \%$ тратится на досуг, творчество, созидание. Современная эпоха характеризуется стремительным ростом уровня потребления энергии, особенно в высокоразвитых странах. Каждые 12 лет количество потребляемой энергии удваивается. При этом рост производства увеличивается вдвое только каждые 15 лет. Объясняется это несоответствие растущим уровнем комфортности на производстве и в быту.

Современное человечество бездумно расходует запасы ценнейшего сырья, которое понадобится будущим поколениям для переработки в препараты, материалы и различные средства.

Быстро растущее потребление энергоносителей при постоянном уменьшении их за- 
пасов в недрах планеты вызывает серьезное беспокойство. Одной из причин повышения энергоемкости экономики является индустриализация.

История индустриального развития человечества характеризуется 4 яркими эпохами. В каждой эпохе выделяются 3 этапа: формирования, бурного роста и стабилизации. Продолжительность этапа бурного развития в среднем пол столетия. Эпохи носят названия тех технологий, которые были приоритетными, и стимулировали развитие целого ряда отраслей техники. Каждая эпоха требовала принципиально новых, революционных научных и технологических решений.

В 1939 г. на смену индустриальным революциям пришла информационная революция, свидетелями бурного развития которой мы являемся. Однако к 2025г. ее революционный характер будет вычерпан, эти технологии не станут диктовать задачи науке и технике. Ей на смену придут нанотехнологии. Их начало было положено в 1997г. Ричардом Фейманом. Уже сейчас доказана высокая практическая эффективность нанотехнологий в различных сложнейших задачах.

Человек на протяжении всей истории развития стремился повысить уровень комфортности своей жизни. Ту степень комфорта, которую достиг человек, практически трудно снизить. Да это и не логично в тенденциях развития человечества. Естественно стремление слаборазвитых стран повысить уровень комфорта до западных стандартов. Естественно желание европейца улучшить жизненные показатели. Однако для этого требуется увеличить расход ресурсов, в первую очередь - энергии. Добыча энергоносителей, их переработка неизбежно оказывают отрицательное влияние на среду обитания человека. Повышение качества жизни приводит к росту нагрузки на окружающую среду. Парадоксально, но стремление к комфорту неизбежно без ухудшения условий среды обитания. Какой он - разумный баланс, можно ли разумней использовать энергоресурсы? Как расходовать только совершенно необходимое количество энергии при сохранении достигнутого уровня комфорта и, даже, повышать его.

Для удовлетворения растущих требований комфортности в быту, в сфере услуг и на производстве (отопление, автоматизация, кондиционирование воздуха, использование информационных технологий и пр.), челове- чество расходует все больше и больше энергии, соответственно возрастает нагрузка на окружающую среду.

Мы уже на пороге нового противоречия современный уровень добычи и переработки энергоносителей привел к серьезным проблемам с защитой окружающей среды. Загрязнение среды обитания противоречит условиям комфортности. Следует незамедлительно искать пути резкого сокращения расходов энергоносителей, загрязнения окружающей среды при повышении уровня комфортности человечества.

Высокий уровень потребления энергии в стране и низкий уровень комфорта свидетельствуют о расточительстве при использовании энергоносителей. В мире в производстве полезно используется только 1/3 сырья. Поэтому, проблема эффективного использования сырьевых ресурсов тоже является глобальной. За последние десятилетия промышленная нагрузка на окружающую среду выросла в 2,5...3 раза. Формируются проблемы «следов человека в планетарной экосистеме». Вызывают тревогу стремление человека к бесконечному росту населения на конечных масштабах планеты. Проблемы обеспечения человечества ресурсами требовали серьезных исследований.

Первым серьезно анализировать эти глобальные проблемы стал крупный бизнесмен, впоследствии видный общественный деятель, Аурелио Печчеи. Именно он, по личной инициативе, в 1968г. организовал, и стал первым президентом необычной международной, неправительственной общественной организации «Римский клуб» (РК). Основной целью РК стали исследования глобальных экологических, экономических, социальных и политических проблем и выработка практических рекомендаций по их преодолению. Основными задачами РК стала широкая просветительская деятельность среди населения, и оказание соответствующего влияния на лиц, принимающих решения на международном уровне. При этом Римский клуб изначально не связан с каким-либо государством, организацией или политической партией. Нет у него и постоянного бюджета, так как, по мнению создателей организации, это могло бы ограничивать свободу их действий.

Широкий резонанс имела разработанная учеными клуба глобальная прогнозная модель развития человечества, которая получила название «модель Римского клуба» [3]. 
Модель отличалась существенной новизной, как в методологическом ключе, так и в формировании нового научного направления теоретические основы глобалистики. При разработке модели учитывались такие определяющие показатели общества как запасы органического топлива, смертность, рождаемость, население планеты, производство товаров, объем услуг, нагрузка на окружающую среду. Определялись тенденции их изменения за 70 лет развития человечества. Дальше строились сценарные модели по принципу «что ожидать, если будет развитие таким». Всего составлено 12 сценариев. Первый (самый пессимистичный) сценарий определял, что, если все тенденции сохранятся и не будут найдены дополнительные источники энергии, то в 2030г. человечество ожидает острейший энергетический кризис [3].

Последующие сценарии проводились с нарастающим оптимизмом. Авторы предполагали, что со временем будут найдены новые источники энергии, снизится нагрузка на окружающую среду. Авторы не указывали пути, как это сделать, просто рассматривались ситуации, если это произойдет. В этих ситуациях кризисы смягчались и отодвигались во времени. Однако, всегда проблемы энергии, экологии и пищи оставались ключевыми. Последний сценарий являлся стабилизационным, были установлены уровни анализируемых параметров, которые обеспечат устойчивое и стабильное существование общества.

Таким образом, глобальная прогнозная модель «Римского клуба» [3] определила приоритеты развития человечества в XXI веке. В ближайшем будущем до 2030 года прогнозируется решение задач обеспечения мировой экономики энергией и обострение следующей проблемы - роста нагрузки на окружающую среду [2].

Таблица $1^{1}$.

Периоды формирования глобальных кризисов ${ }^{2}$

\begin{tabular}{|c|c|c|c|}
\hline \multirow{2}{*}{ Кризисы } & \multicolumn{3}{|c|}{ Периоды } \\
\cline { 2 - 4 } & Развития & Роста & $\begin{array}{c}\text { Стабили- } \\
\text { зации }\end{array}$ \\
\hline Энергии & $1970-2000$ & $2000-2020$ & $2020-2030$ \\
\hline Экологии & $2010-2030$ & $2030-2050$ & $2050-2070$ \\
\hline Пищи & $2040-2060$ & $2060-2080$ & $2080-3000$ \\
\hline
\end{tabular}

К концу столетия нас ожидает масштабный продовольственный кризис. Концептуальная идея модели «Римского клуба» может быть выражена схемой (табл. 1). Каждый кризис формируется из трех этапов: развитие, бурный рост и стабилизация на достигнутом уровне.

В настоящее время человечество активно ищет решение проблемы энергетической эффективности. Наиболее остро эти задачи характерны для стран, которые из энергорасточительных, но энергообеспеченных, оказались энергодефицитными странами, но до сих пор осталась энергорасточительными. Высокий уровень потребления энергии в таких странах и низкий уровень комфорта свидетельствуют о расточительстве при использовании энергоносителей.

Поэтому, энергетический кризис в таких странах развивается чрезвычайно остро. Особенно, если в стране отсутствуют научно обоснованные энергетические программы, нет действенной системы энергоменеджмента.

\section{ПРОГНОЗ РАЗВИТИЯ ЭНЕРГЕТИ- ЧЕСКИХ ПРОБЛЕМ В МИРЕ}

Предпосылок снижения цен на энергоносители - нет. Цены на уголь останутся практически на одном уровне. Цены на нефть и газ будут стабильно расти. Надежды на решение проблемы энергообеспечения за счет альтернативных источников энергии весьма проблематичны.

Несмотря на то, что в последние годы постоянно вводятся в эксплуатацию новые комплексы с возобновляемыми источниками энергии, их доля в энергетическом балансе не увеличивается. Прогнозируется, что в обозримом будущем доля возобновляемых источников энергии не превысит $10 \%$ в общем энергетическом балансе планеты. А структура потребления энергоресурсов в мире останется прежней. Минеральное топливо будет оставаться в цене и преобладать в мировой структуре энергопотребления.

Однако, себестоимость производства наиболее дорогого ресурса - электроэнергии будет снижаться. Эксперты считают, что стоимость транспортировки угля будет расти существенней, чем газа и нефти. Либо потребуется строить мощные сети электропередач и подстанций, что недешево.

Строительство новых ядерных станций с учетом создания полностью новой инфраструктуры слишком дорого и не по плечу теперь даже США. В настоящее время в мире 
работает 191 атомная электростанция с 450 реакторами.

Наиболее дорогая электроэнергия сейчас на солнечных фотостанциях и при использовании топливных элементов. Наиболее дешевая - на угольных станциях.

При этом, к 2025 г. за счет обеспечения максимума загрузки, новых мощностей и новых технологий эксперты ожидают снижение себестоимости генерации электроэнергии. При экспертизе учтены факторы влияния, связанные с эволюцией техники и новых технологий: ввод новых экономичных мощностей, системная оптимизация уровня и равномерности загрузки станций, рост цен.

Следует обратить внимание на фантастическое снижение себестоимости солнечных фотостанций (в 7 раз!). На совершенствование таких экологически чистых прямых преобразователей солнечной энергии в электричество в развитых странах затрачиваются большие средства. В основе новых конструкций таких фотоэлектрических сборок нанотехнологии.

Чрезвычайно важную роль играет энергетическая политика государства. Это должна быть энергетическая эффективность, а не энергосбережение. Именно энергоэффективность является тем направлением, которое стимулирует развитие производства, внедрение прогрессивных технологий и обеспечивает комфортные условия жизни населения.

В условиях энергетического кризиса важно правильно выбрать стратегию развития. Если в прошлом страна была пресыщена дешевыми энергетическими ресурсами, то это не развивало уважения к энергии, способствовало формированию пренебрежительного отношения к задачам энергоэффективности. Пока в стране не будет преодолен барьер чрезвычайно низкой культуры энергопользования, никакие программы энергосбережения работать не будут.

Поэтому, одним из приоритетных направлений энергетической политики государства должно стать обучение культуре энергопользования всех слоев населения: от первых лиц регионов, предприятий до студентов и школьников.

\section{РАЗВИТИЕ КОНЦЕПЦИИ «РИМСКОГО КЛУБА»}

Полувековой опыт работы Римского клуба позволяет сделать ряд прогнозируемых и неожиданных выводов, установить достиже- ния и вопросы, которые не удалось решить. Безусловными являются теоретические и методологические достижения Клуба. Именно в РК пришло осознание глобального характера происходящих в мире перемен и обострение проблем планетарного масштаба. Именно в РК прошло становление и развитие глобалистики как междисциплинарной области научного знания, созданы теоретические основы глобалистики.

Именно в РК впервые и весьма эффективно использовалось глобальное моделирование, которое получило широкое развитие в компьютерных моделях социальноэкономических задач в математическом моделировании системы «общество - природа».

Представляется, что в каждой стране, отрасли, регионе, городе, на предприятиях следует обосновать прогнозную модель развития, которая обязательно бы учитывала проблемы обеспечения ресурсами, их развитие и специфику. Только на основе серьезного прогнозирования можно строить текущую политику модернизации производства, роста эффективности экономики и повышения продолжительности и качества жизни населения. Формирование таких прогнозных моделей требует корректного учета всех определяющих показателей, оценки тенденций их развития, увязки с геополитическими и экономическими проблемами. Естественно, это фундаментальная работа, но она крайне необходима для обеспечения будущего отрасли, предприятия. Методы построения прогнозных моделей предполагают системный подход и структурный анализ. Энергетическая и экологическая составляющие таких моделей разрабатываются с привлечением принципов энергетического и экологического менеджмента. Особенно важно это учитывать на стадии проектирования инновационных технологий, особенно, для производства продуктов питания.

Исследования РК представлены в 44 докладах, последние из которых $[4,5]$. Даже названия докладов [3-11] подчеркивают глубокий анализ глобальной проблематики. Доклады имели широкий общественный резонанс, однако за все время РК так и не удалось хоть как-либо улучшить состояние планеты. При этом РК за активную деятельность общепризнан как центр в области мировых глобальных исследований. Сам А. Печчеи удивлялся, что люди не готовы выделять ради бу- 
дущего планеты ни денег, ни времени, ни возможностей своего общественного престижа. Таким образом, глобальное противоречие настоящего времени - повышение темпов роста населения планеты при сокращении ресурсов, и наращивании роста экологических проблем неизбежно приведет к коллапсу существующего мирового порядка. Весьма вероятно, что энтузиазм ученых несколько усилил остроту этих противоречий.

Инструментом действий РК были призывы и обращения. А кто их мог услышать? Население слаборазвитых стран, которые страдают от войн за ресурсы планеты? Мигранты из этих стран, которые стремятся к беспечной и более комфортной жизни, и которых уже более 60 млн.? Обыватели развитых стран, для которых парадигмы РК заоблачные? Политики, которым эта тема не повысит рейтинги? Олигархи, для которых проблема глобализации не принесет прибыли? Мировая элита, которая, в угоду меньшинству для решения глобальных задач проверяет инструменты паники, страха, пандемии?

В отдельно взятой богатой и процветающей социалистической или монархической стране с прогрессивным правителем такие изменения могут произойти. Для развитых капиталистических стран необходимы поколения для воспитания новой философии природопользования. Вероятно, необходимо искать новую парадигму развития цивилизации, которая опиралась бы на достижениях научно-технического потенциала, на новой платформе, которая должна прийти. Такой платформой может стать нанотехнологическая революция. При создании РК о возможностях нанотехнологий не говорили, в моделях РК инновационный фактор вообще не брался во внимание. Согласование глобальных задач планеты с современными сложившимися взглядами и движущей силой экономики капиталистических стран должно решить проблемы глобализации. Концепция такой модели должна быть однозначной: глобальными задачами должно быть заниматься выгодно. При этом необходимо конкретизировать специфичные задачи, которые определяются отраслью экономики, сферой жизни.

В дальнейшем сосредоточимся на агропромышленном комплексе, где все глобальные проблемы человечества проявляются наиболее ярко.

\section{МЕХАНИЗМ ГИБРИДНОГО ПРОЦЕССА}

В настоящее время динамично растет интерес к технологиям адресной доставки энергии. Уделяется серьезное внимание энергетической эффективности процессов концентрирования $[14,15]$, использованию микроволновой техники в задачах совершенствования выпарной [17] и сушильной техники [18-21] в пищевых технологиях.

Технологии адресной доставки энергии позволяют организовать гибридный процесс, который обеспечит точечное парообразование и скачкообразный рост давления. В результате произойдет механический выход потока жидкости из объема твердой фазы. В качестве инновационных источников энергии рассматриваются электромагнитные генераторы микроволнового диапазона, которые реализуют гибридный процесс. Целевой компонент $(C)$ из объема сырья извлекается двумя потоками (рис. 1). Первый - это традиционный, диффузионный ( $J d)$. Второй - это специфический поток ( $J b)$, движущей силой которого является разность давлений, возникающая в результате локальной диссипации электромагнитной энергии в объеме сырья. Таким образом, именно поток электромагнитной энергии инициирует гидравлический поток ( $J b)$. Это - бародиффузия, механизм которой доказан, и иллюстрируется схемой (рис. 1).

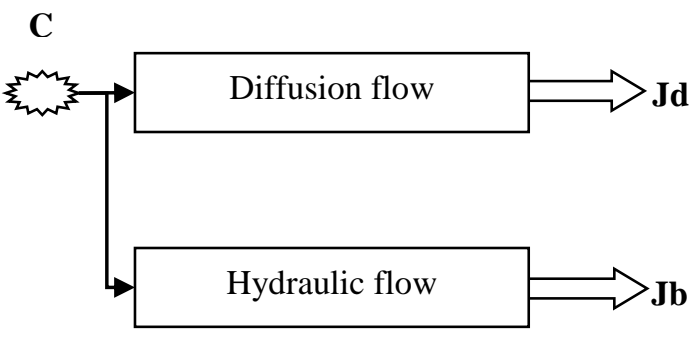

Рис. 1. Схема гибридного процесса. ${ }^{3}$

Поток $J b$ способен на порядки превышать традиционные принципы интенсификации (табл. 2).

Факты, подтверждающие эффективность бародиффузионных и механодиффузионных технологий свидетельствуют о революционных возможностях гибридных процессов в пищевых технологиях. Организация гибридных процессов является мощным инструментом для перевода пищевой индустрии на рельсы нанотехнологий. 
Таблица $2^{4}$.

Степень интенсификации процессов переноса $^{5}$

\begin{tabular}{|c|l|c|}
\hline № & \multicolumn{1}{|c|}{$\begin{array}{c}\text { Принцип } \\
\text { интенсификации }\end{array}$} & $\begin{array}{c}\text { Эффект } \\
\text { интенсификации }\end{array}$ \\
\hline 1 & $\begin{array}{l}\text { Специальная обра- } \\
\text { ботка поверхности }\end{array}$ & до 2 раз \\
\hline 2 & $\begin{array}{l}\text { Применение } \\
\text { ультразвука }\end{array}$ & в $2 \ldots 3$ раза \\
\hline 3 & $\begin{array}{l}\text { Использование элек- } \\
\text { трического поля }\end{array}$ & в $3 \ldots 4$ раза \\
\hline 4 & Закрутка потока & в $6 \ldots 8$ раз \\
\hline 5 & Вращение реактора & в $25 \ldots 30$ раз \\
\hline 6 & Вибрация & в $30 \ldots 35$ раз \\
\hline 7 & Бародиффузия & на $2 \ldots 3$ порядка \\
\hline
\end{tabular}

\section{РАЗВИТИЕ МОДЕЛИ «РИМСКОГО КЛУБА»}

Концептуально развитие глобальных кризисов, по прогнозам Римского клуба, с периодами зарождения, бурного роста и стабилизации предлагается выразить моделью (рис. 2).

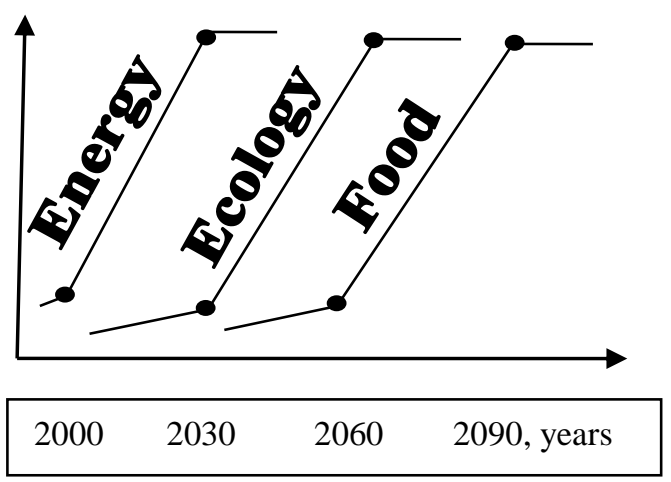

Рис. 2. Формирование глобальных кризисов в модели Римского клуба. ${ }^{6}$

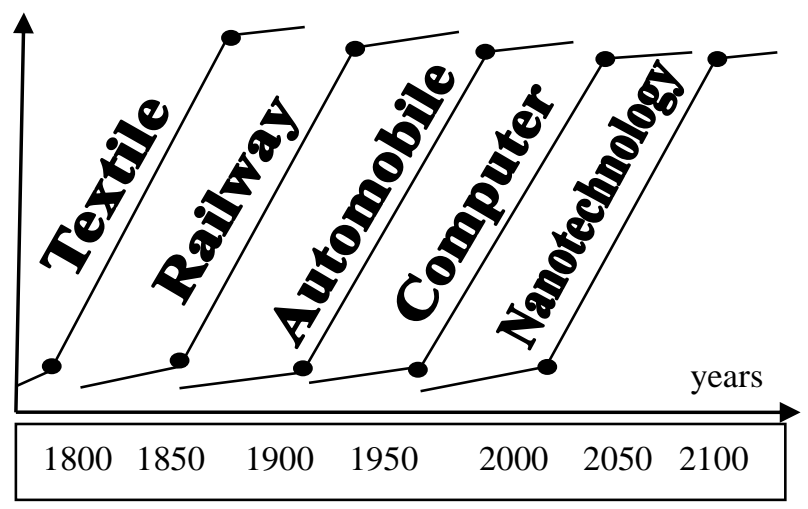

Рис. 3. Формирование эпох индустриального развития. ${ }^{7}$
Представляется, что эпоха нанотехнологий может серьезно скорректировать развитие глобальных кризисов.

Интересно, что закономерности формирования кризисов и эпох индустриализации похожи (рис. 2-3).

\section{НОВАЯ ПАРАДИГМА РАЗВИТИЯ ЧЕЛОВЕЧЕСТВА}

Основные глобальные проблемы человечества наиболее остро касаются технологий производства пищи: это и энергетика, и экология, и непосредственно продукты питания [12, 13]. Агропромышленный комплекс (АПК) развит абсолютно во всех странах, и занимает лидирующие позиции, как по уровню потребления энергетических ресурсов, так и по нагрузке на окружающую среду. Поставим задачу управления процессами развития кризисов с привлечением инноваций наноиндустрии. Выдвигается идея, проблемы энергетики, экологии и пищи целесообразно решать в комплексе, параллельно, а не последовательно. Следует инициировать уже сегодня комплексное решение вопросов: «глубокая переработка пищевого сырья получение резервной пищи - снижение нагрузки на среду обитания - переработка оставшейся биомассы на топливные пеллеты». Тогда периоды роста экологичного и, особенно, кризиса пищи будут не столь стремительны, кризисы будут протекать мягче со смещением во времени на 10-40 лет (рис. 4). А могут, даже, приблизиться к модели стабилизации.

Эффективным инструментом управления развитием кризисов может стать наноиндустрия.

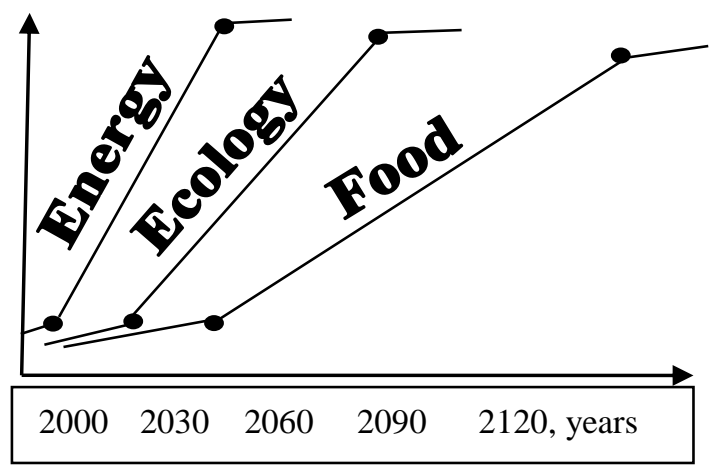

Рис. 4. Управление развитием глобальных кризисов. ${ }^{8}$ 
Новая парадигма развития общества формулируется так: «концентрацию ресурсов общества и научного потенциала следует, вопервых, направить на создание пищевой наноиндустрии, что сможет эффективно в комплексе решать проблемы безотходных пищевых технологий, - обеспечит дополнительные полноценные резервы пищи при резком снижении нагрузки на окружающую среду, и получению дополнительных источников энергии на основе топливных элементов из биомассы».

В странах с социалистической экономикой эти положения могут усилиться энтузиазмом общества, стать частью национальной идеи. В капиталистических странах парадигма рассчитывает на высокую рентабельность проектов.

Таким образом, безотходные пищевые технологии смогут не только решать проблемы экологической безопасности производства, но и резервных источников пищи. Однако решение этих проблем требует революционных преобразований в пищевой отрасли. Необходим переход к принципиально новым технологическим приемам. Производство неэнергоемких пищевых продуктов повышенной пищевой ценности, создание ассортимента новых образцов, глубокая переработка пищевого сырья однозначно требуют использования современных приемов в технологиях. И их основой станут нанотехнологии.

Комплексно проблемами пищевых нанотехнологий в мире занимаются ограничено. Вместе с тем, пищевое сырье это созданные природой наноразмерные структуры, которые при переработке необходимо разрушить с минимальными затратами энергии и при максимальном сохранении пищевой ценности. Использование нанотехнологий в пищевой промышленности позволит создать принципиально новые продукты, не имеющие аналогов в современной кулинарии.

\section{РЕШЕНИЕ ЭНЕРГЕТИЧЕСКИХ ПРОБЛЕМ}

Производство пищи является энергоемкой отраслью во всех индустриально развитых странах. Пищевые технологии развиваются по пути стабильного роста уровня потребления энергетических ресурсов. Если ввести понятие энергетический КПД продовольственной цепочки, то он не превысит 10\%.
Производство продуктов питания в слаборазвитых странах требует затрат энергии в $2 \ldots 5$ раз больше, чем в индустриально развитых странах. Исторические предпосылки тормозят процесс повышения энергетической эффективности как в стране в целом, так и на предприятиях пищевых отраслей, в частности. Часто, экономию можно обеспечить за счет внедрения уже применяемых в мире энергоэффективных мероприятий, процессов и технологий.

Предприятия АПК лидируют по количеству потребляемых энергетических ресурсов среди различных ведомств. До 20\% топливноэнергетических ресурсов в стране расходуется предприятиями АПК. При этом до 40\% энергии в пищевых технологиях может экономиться за счет простых, беззатратных и малозатратных методов. Еще плохо понимается то, что инвестировать энергоэффективные проекты экономически выгодно. Эти инвестиции окупаются на протяжении достаточно короткого времени за счет того, что ежесекундно снижаются расходы энергии, цена которой постоянно растет. На первом этапе модернизаций не так много затрат требуется для того, чтобы существенно снизить расходы энергии на действующем оборудовании. Огромные резервы здесь в ликвидациях привычных для нас прямых потерь ресурсов. Именно они зачастую дают до $75 \%$ потерь энергии. Но и в новых, современных технологиях пока находятся экономически выгодные технические и организационно технические решения по снижению расхода энергетических ресурсов.

Перевод пищевых энерготехнологий на прогрессивные принципы, особенно на нанотехнологии, открывает новые возможности выгодно совершенствовать производство при существенном снижении расхода ресурсов.

Серьезные энергетические проблемы характерны для отраслей, продукция которых требует обезвоживания сырья, а это всегда является энергоемкой технологией. Одновременно ужесточаются требования по безопасности пищевых продуктов [2] и регламентируются экологические условия работы предприятия. Очевидно, что пищевые технологии, следует переводить на инновационные принципы решения энергоэкологических проблем.

Предложенная оценка энергетического КПД, который в пищевой цепочке не превышает $10 \%$, дает основание считать, что резер- 
вы здесь существенны, и, что в таком аспекте вопросы пищи не исследовались.

\section{РЕШЕНИЕ ЗАДАЧ ЭКОИНДУСТРИИ}

Понятия и принципы экоиндустрии завоевывают популярность в развитых странах [4]. Но относительно пищевых технологии - это направление практически не развивается.

Вместе с тем, именно экоиндустрия способна в комплексе решать противоречивые задачи, которые стоят перед современными пищевыми технологиями.

Представляется, что определение этого направления можно сформулировать следующим образом. Экоиндустрия АПК - это последовательная, непрерывная цепь технологических процессов, которые обеспечивают максимальную энергетическую эффективность, минимальные термические воздействия на пищевое сырье, предельно низкую нагрузку на атмосферу и литосферу.

Объединение задач экоиндустрии с возможностями наноиндустрии может изменить мировой порядок в вопросах обеспечения человечества пищей.

Синтез экоиндустриальной технологии должен основываться на современных принципах организации процессов переноса.

Направлением и объектом исследований могут стать «безотходные технологии», приближением к которым являются технологии «Глубокой переработки сырья». То, что мы сейчас выбрасывают на свалки, чем загрязняем атмосферу, гидросферу и литосферу может решать проблемные вопросы планеты.

Так из отходов большинства пищевых и перерабатывающих производств можно получать топливные пеллеты и решать проблемы энергообеспечения. Это не только позволит использовать региональные источники энергии, но и сохранить деревья, которые сейчас вынуждены использовать как топливо.

Отходы пищевых производств - это источник большого количества функциональных компонентов. Извлечение их и реализация имеют несомненные бизнес-перспективы.

Отходы большинства пищевых и аграрных технологий - это полноценные резервы пищи. Следовательно, переработка этих отходов в комплексе решает проблемы экологии, энергообеспечения и пищи.

Это защищает актуальность направления и его стратегическую роль в решении проблем глобализации.

\section{ДОСТИЖЕНИЯ В ОБЛАСТИ ПИЩЕВЫХ НАНОЭНЕРГО- ТЕХНОЛОГИЙ}

Современные проблемы энергоэффективности, глубокой переработки пищевого сырья с полным использованием его пищевого потенциала, экологии производства и безопасности пищевого продукта решаются в плоскости поиска новых принципов организации процессов тепломассопереноса, использования уникальных возможностей комбинированных воздействий на процессы переноса, формирования сложных комбинаций движущих сил направленных на эффективное извлечение целевых компонентов из сырья. особенное внимание уделяется микро- и наноразмерным структурам сырья, которые в традиционных технологиях вообще не рассматриваются. В настоящее время сформулированы и доказаны: парадигма пищевых нанотехнологий, научные концепции термического парадокса, открыты эффекты «механодиффузии» и «бародиффузии». Эти концепции стали основой системы технологий, которые решают общую проблему и используют следующие подходы:

- принципы адресной доставки энергии к элементам пищевого сырья, в том числе и наноразмерным;

- наноэнерготехнологии;

- электродинамические технологии;

— вакуумные и волновые технологии;

- комбинированные и гибридные процессы для инициирования эффектов «механодиффузии» и «бародиффузии».

Разработаны и апробированы конструкции уникального оборудования, которое реализует эффект «механодиффузии». При производстве коньячных спиртов электромагнитный экстрактор проточного типа обеспечил интенсификацию процесса в 1000 раз. При экстрагировании из зерен кофе степень извлечения компонентов увеличена на $15 \%$, а расход энергии снижен на 50\%. Получены экологически безопасные образцы жидкого дыма, амарантового масла с высоким содержанием сквалена. Технологии адресной доставки энергии позволили получить чистую воду с содержанием солей не выше 4мг/кг.

Разработаны конструкции вакуумных электродинамических аппаратов: сушилки, выпарки, экстрактора. Это инновационное оборудование, которое способно перевести пищевые технологии на новейшие принципы, 
обеспечить высокое качество продукта при значительном уменьшении энергетических затрат.

Разработанный выпарной аппарат не имеет ограничений по конечной концентрации продукта, он функционирует и дает стабильные параметры по производительности выпаривания до (90-95) orix. Для него отсутствуют типичные проблемы теплопередачи. Апробирован аппарат для получения безалкогольного вина, обезвоживания морепродуктов. Созданы ленточная ИК сушилка, деалкоголизатор, тепломассоутилизатор, пиролизная установка, криоконцентратор, и т.п.

Опытные образцы инновационных продуктов, полученных на этом оборудовании, имеют высокие вкусовые характеристики. Получены: сушеные овощи, фрукты, чипсы, слайсы, пасты, жидкий концентрат кофе, криоконцентраты соков, молока и экстрактов (50하스), порошок мяса.

Из отходов пищеконцентратных консервных, винодельческих производств получено фруктовую и безглютеновую муку, топливные пеллеты. Получено порошки лука, чеснока, экологично безопасный концентрат жидкого дыма, масла, водный 97\% концентрат экстракта кофеина, фруктовые эссенции, гидролаты, бальзамы и пр.

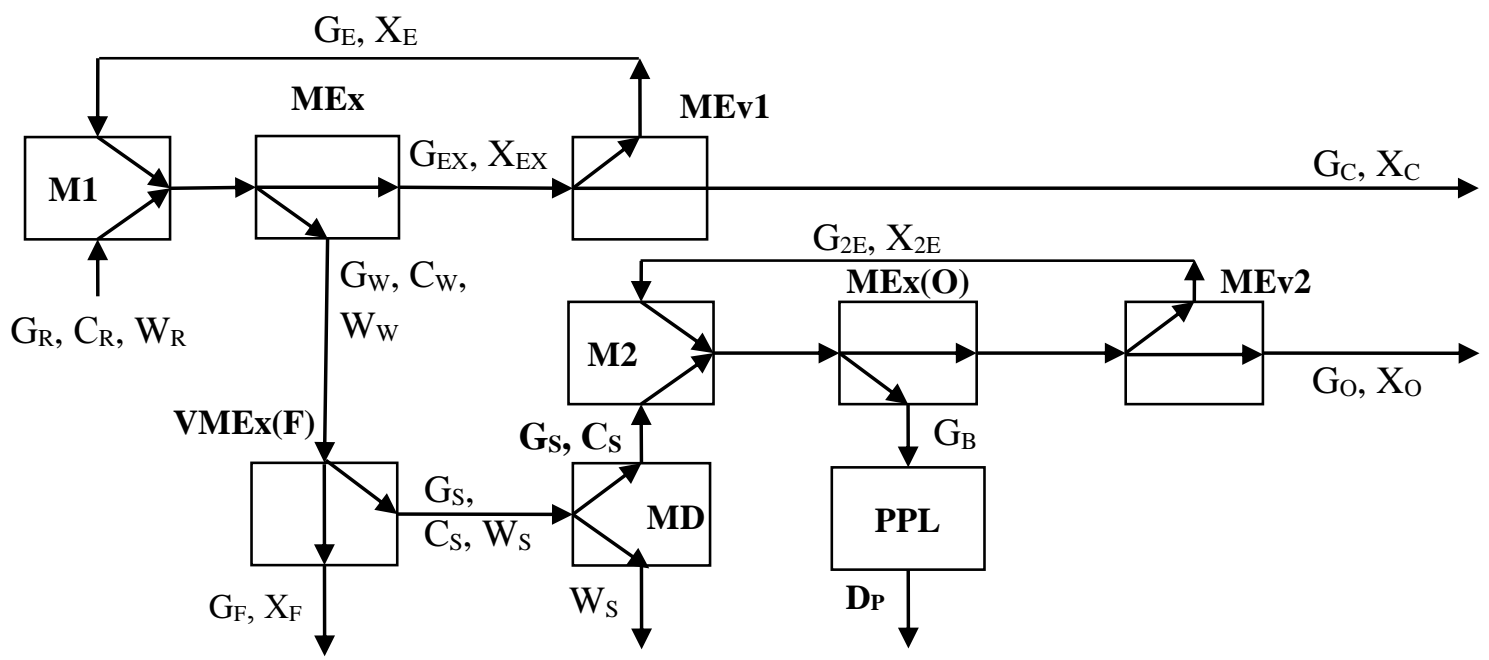

Рис. 5. Схема материальных потоков при глубокой переработке растительного сырья. 9

Пищевые продукты, полученные по предложенным принципам, практически полностью сохранят функциональные свойства сырья, их производство потребует меньших затрат энергии, а глубокая переработка и безотходные технологии сведут до минимума нагрузку на окружающую среду.

Рассмотрим типичную схему экстракционного цеха и предложения по глубокой переработке отходов (рис. 5). Растительное сырье (расход которого $G_{R}$, общее содержание целевых компонентов $C_{R}$ и влагосодержание $W_{R}$ ) смешивается с экстрагентом (расход которого $G_{E}$, содержание сухих веществ $X_{E}$ ) и поступает в экстрактор $\boldsymbol{M E \boldsymbol { E }}$. Здесь из сырья в раствор переходит часть целевых компонентов и получается экстракт Gex c концентрацией $X_{E X}$. B выпарном аппарате MEv1 удаляется часть растворителя и полу- чается концентрат $\left(G_{C}, X_{C}\right)$. Из экстрактора выгружаются отходы с параметрами $G_{W}$, $C_{W}, W_{W}$. Как правило, эти отходы являются агрессивными загрязнителями окружающей среды, при этом они содержат достаточное для переработки количество целевых компонентов. Однако традиционные технологии экстрагирования не в состоянии их извлекать, поскольку сосредоточены они в микрокапиллярах. Задача решается, если привлечь предложенные ранее автором технологии адресной доставки энергии и организовать инновационные процессы массопереноса из отходов (рис. 5).

Отходы традиционных технологий $\left(G_{W}\right)$ содержат комплекс термолабильных функциональных компонентов, и, например, масла, которые извлекаются и другим экстрагентом, и на другом уровне температур. Поэтому, ин- 
новационная схема предусматривает два экстрактора — вакуумный $(\boldsymbol{V M E x}(\boldsymbol{F}))$ для извлечения функциональных компонентов, и микроволновой экстрактор для масла $(\boldsymbol{M E x}(\boldsymbol{O}))$. Из вакуумного экстрактора выходят функциональный компонент $\left(G_{F}\right)$ и шлам $\left(G_{S}\right)$. В микроволновой сушилке из шлама удаляется влага $\left(W_{S}\right)$ и обезвоженный шлам поступает в микроволновой экстрактор масла $(\boldsymbol{M E x}(\boldsymbol{O}))$. Из биосырья $\left(G_{B}\right)$ на линии производства пеллет (PPL) получают топливные элементы $\left(D_{P}\right)$, а в микроволновом выпарном аппарате ( $\boldsymbol{M E \boldsymbol { V } 2}$ ) - концентрат масла $\left(G_{O}, X_{O}\right)$. Таким образом, кроме традиционного концентрата $\left(G_{C}\right)$ идет глубокая переработка сырья и ставится задача дополнительно получить: жидкий концентрат функциональных компонентов $\left(G_{F}\right)$, пеллеты $\left(D_{P}\right)$ и масло $\left(G_{O}\right)$. Причем коммерческая стоимость этих продуктов часто выше, чем традиционного концентрата.

\section{ЗАКЛЮЧЕНИЕ}

Развитие теоретических положений глобализации, заложенных в работах Римского клуба, требует перехода в плоскость практических приложений. Представляется, что такие конкретные предложения не могут быть одинаковыми для всех сфер экономики, для всех стран и народов. Предлагается начать практические преобразования в пищевой индустрии. Именно эта отрасль является ярким примером, где и энергетика, и экология, и пища требуют незамедлительных инноваций во всех странах. Внедрение безотходных технологий переработки пищевого сырья позволит решить экологические проблемы и получить новые резервы пищи. А биомасса станет основой получения топливных элементов, пеллет. Кроме того, именно пищевые производства «работают» с созданными природой наноразмерными структурами. Поэтому революционные технологические преобразования проще начинать здесь. Более того, именно в этом направлении уже есть успешные наработки в Украине. Успехи и достижения в области эко- и наноиндустрии пищевых производств станут эффективным стимулом внедрения инноваций и в других сферах деятельности человечества.

\section{APPENDIX 1 (ПРИЛОЖЕНИЕ 1)}

${ }^{1,2}$ Table 1. Periods of global crises formation.

${ }^{3}$ Fig. 1. Scheme of hybrid process. ( $C-$ target component, $J d$-diffusion flow, $J b-$ hydraulic flow).

4,5 Table 2. Level of transfer processes intensification.

${ }^{6}$ Fig. 2. Formation of global crises in the Club of Rome model.

${ }^{7}$ Fig. 3. Formation of empires of industrial development.

${ }^{8}$ Fig. 4. Management of global crises development.

${ }^{9}$ Fig. 5. The scheme of material flows during deep treatment of food raw material $(M 1-$ mixer 1 , $G_{R}$ - raw material mass, $C_{R}$ - concentration of target components in raw material, $W_{R}$ - moisture content in raw material, $G_{E}-$ extractant mass, $X_{E}$ - concentration of target components in extractant, $G_{E X}$ - extract mass, $X_{E X}$ - concentration of target components in extract, $M E v 1$ - microwave evaporator $1, \quad G_{C}-$ concentrate mass, $X_{C}$ - concentration of target components in concentrate, $G_{W}$ - waste mass, $C_{W}$ - concentration of target components in waste, $W_{W}$ - moisture content in waste, $\operatorname{VMEx}(F)$ - vacuum microwave extractor of functional components, $G_{E}$ - functional component concentrate mass, $X_{E}$ - concentration of functional component in concentrate, $G_{S}$ - sludge mass, $C_{S}$ - concentration of target components in sludge, $W_{S}$ - moisture content in sludge, $M D$ - microwave dryer, $M 2-$ mixer 2, $G_{2 E}-$ extractant mass, $X_{2 E}$ - concentration of target components in extractant, $M E x(O)$ - microwave oil extractor, $G_{B}$ - biomass, $P P L$ - pellet production line, $M E v 2$ - microwave evaporator $2, G_{C}$ - oil concentrate mass, $X_{C}$ - concentration of oil in concentrate).

\section{Литература (References)}

[1] Clapp J., Newell P., Brent Z. W. (2018). The Global Political Economy of Climate Change, Agriculture and Food Systems. The Journal of Peasant Studies, 45(1), 80-88.

[2] Weststrate J.A., G. van Poppel, P.M. Verschuren /Functional Foods, Trend and Future British J. Nutrition. 2002. - V.88. Suppl.2.1 - 233-235.

[3] Meadows et al. The Limits to Growth: a Report to the Club of Rome. - 1972.

[4] Weizsäcker E., Wijkman A. Come On! Capitalism, Short-Termism, Population and Destruction of the Planet: a Report to the Club of Rome. 2018.

[5] Kuenkel P. Stewarding Sustainability Transformation: a Report to the Club of Rome. - 2019.

[6] Mesarovic M., Pested E. Mankind at the Turning Point: a Report to the Club of Rome. - 1975. 
[7] Tinbergen J. Rio. Reshaping the International Order: a Report to the Club of Rome. - 1976.

[8] Gabor D., Colombo U., King A. S. Beyond the Age of Waste: a Report to the Club of Rome. 2016.

[9] Laszlo E. et al. Goals for Mankind: a Report to the Club of Rome. - 1977.

[10] Bofgese M. The Future of the Oceans: a Report to the Club of Rome. - 1986.

[11] King A. The First Global Revolution: a Report to the Club of Rome. - 1991.

[12] Goodman E.M., Redmond J., Elia D., Harris S.R., Augustine M.B., Hand R.K. Practice Roles and Characteristics of Integrative and Functional Nutrition Registered Dietitian Nutritionists. Journal of the Academy of Nutrition and Dietetics, 2018, vol. 118, no. 12, pp. 2356-2369. doi: 10.1016/j.jand.2018.03.027.

[13] Liu W., Zhang M., Bhandari B. Nanotechnology - A Shelf life Extension Strategy for Fruits and Vegetables. Critical Reviews in Food Science and Nutrition, 2019, vol. 60, no. 10, pp. 17061721. doi: 10.1080/10408398.2019.1589415.

[14] Sabanc1 S., Icier, F. Effects of Vacuum Ohmic Evaporation on Some Quality Properties of Sour Cherry Juice Concentrates. International Journal of Food Engineering, 2019, vol.15, no.9, pp. 1-8. doi:10.1515/ijfe-2019-0055.
[15] Almena A., Goode K.R., Bakalis S., Fryer P.J., Lopez-Quiroga E. Optimising Food Dehydration Processes: Energy-Efficient Drum-Dryer Operation. Energy Procedia, 2019, vol. 161, pp. 174-181. doi: 10.1016/j.egypro.2019.02.078

[16]Bozkir H., Baysal T. Concentration of Apple Juice Using a Vacuum Microwave Evaporator as a Novel Technique: Determination of Quality Characteristics. J Food Process Eng, 2017, pp. 19. doi: 10.1111/jfpe.12535.

[17] Pattnaik M., Mishra H.N. Effect of Microwave Treatment on Preparation of Stable PUFA Enriched Vegetable Oil Powder and Its Influence on Quality Parameters. Journal of Food Processing and Preservation, 2020, vol. 44, no. 4, pp. 1-15. doi: 10.1111/jfpp.14374.

[18] Kumar C., Karim M. A. (2019). MicrowaveConvective Drying of Food Materials: A Critical Review. Critical reviews in food science and $n u-$ trition, 59(3), 379-394.

[19] Monteiro, Ricardo L., et al. (2018). Microwave Vacuum Drying and Multi-Flash Drying of Pumpkin Slices. Journal of food engineering, 232, 1-10.

[20] Adarsh, M., Kalla Devaraju, R., Microwave Energy and Its Application in Food Industry: A review, Asian J. Dairy Food Res., 2017, vol. 36, no. 1, p. 37. doi: 10.18805/ajdfr.v0iOF.7303

\section{Сведения об авторе.}

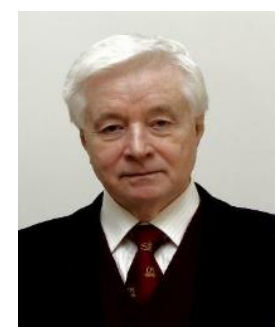

\section{Бурдо Олег Григорьевич,}

доктор техн. наук, профессор. Сфера научных интересов: процессы тепломассообмена, нанотехнологии в пищевой промышленности, энергоэффективность

г. Одесса, Украина

E-mail: poem.onaft@gmail.com 